\title{
A Study on the Housing and Feeding Management Practices Followed by Rural Milk Producers of Telangana State
}

\author{
K. Kalyani, R.M.V. Prasad, Suresh Rathod, P. Jaya Laxmi \\ Department of Livestock Production and Management, \\ College of Veterinary Science, Rajendranagar-500 030, Hyderabad, Telangana, India.
}

Received: July 2021

Accepted: August 2021

\begin{abstract}
An investigation was carried out to study the housing and feeding management practices followed by the dairy farmers in five districts of Telangana state. From each district one mandal and from each mandal five villages were selected. The data was collected from 150 farmers through personal interview utilizing a schedule developed for the purpose. It was observed that most of the dairy farmers (59.33\%) had medium herd size and $59.33 \%$ of farmers housed their animals beside their houses while $14.67 \%$ and $26 \%$ of the farmers housed the animals in a separate shed and below the shade of tree, respectively. Most of the animal sheds (66\%) in the study area had mud flooring. Majority of farmers (52\%) were not taking any measures to protect animals from extreme heat in summer. Grazing and group feeding were most commonly practised except in Rangareddy district where most of farmers $(56.67 \%)$ followed individual feeding. Majority of the farmers from Medak (50\%) and Mahaboobnagar (60\%) districts were following one time feeding of their animals, whereas, most farmers from Vikarabad (66.67\%) fed two times in a day. In Rangareddy and Nalgonda, majority (66.67\% and 63.33\%) of the farmers were offering feed three times. Most of the farmers were producing fodder by themselves in Vikarabad, Medak, Nalgonda and Mahaboobnagar districts and their percentages were 66.67\%, 63.33\% 93.33\% and 86.67\%, respectively. Most of the farmers of Rangareddy district were procuring fodder from outside.
\end{abstract}

Key words: Dairying, Dairy farmers, Feeding, Housing.

\section{INTRODUCTION}

Dairying in India is closely knitted as an integral part of agriculture, playing an indispensable role in the upliftment of rural poor. Dairy sector is an important source of secondary income for over 80-90 million milk producers in the country. In spite of the fact that cattle and buffalo production systems are largely traditional based, the dairy sector in India has grown substantially over the years with an annual growth rate of above $4 \%$. India stands first in World in terms of milk production. But the performance and productivity of dairy animals appear to be at low level and the factors responsible need greater attention. Productivity of animals is primarily the product of its genetic makeup and the environment provided to it. Scientific management will give scope for efficient utilization of the available resources by the resource crunch poor traditional farmers.

Improved animal husbandry practices play a vital role in the increase of per animal productivity which in turn influences the overall farm profitability. Scientific management will help in keeping the animals healthy and more resistant to the diseases which indirectly help in improving farm efficiency. Published literature indicates that most of the farmers are not aware of scientific animal management practices, a prerequisite for development of dairy industry (Aulakh and Singh, 2015).
Hence, it is felt pertinent to study the housing and feeding management practices followed by the rural milk producers. The five districts of newly formed Telangana state viz., Rangareddy, Mahabubnagar, Vikarabad, Medak and Nalgonda were selected to conduct the investigation, as these districts have a large scope for dairy development and are nearer to the fast developing Hyderabad urban market.

\section{MATERIALS AND METHODS}

The study was conducted in the selected mandals of the five districts which were chosen for the study. From each district one mandal and from each mandal five villages were selected and from each village six farmers were selected, taking the maintenance of dairy animals by the farmer and possessing saleable milk into consideration. Thus a total of one hundred and fifty dairy farmers were selected for the study.

\section{Data collection}

The data was collected from the farmers through personal interview at their door step by utilizing a schedule developed for the purpose. While collecting data sufficient time was given to the farmer to arrive at values by memory recall method. The farmer's family members were also involved

\footnotetext{
${ }^{*}$ Corresponding author's E-mail: rmvprasad16@gmail.com
} 
in collection of the data to add accuracy to the information provided, in the form of discussion. The accuracy of information pertaining to certain management activities was checked and recorded by the investigator by making personal observation also during multiple visits made to the dairy farmer. Information about the management practices followed pertaining to housing and feeding was collected.

\section{RESULTS AND DISCUSSION Housing management practices}

Housing management practices followed by the dairy farmers in selected five districts presented in Table 1 revealed that most of the farmers in all the districts housed their animals beside their houses whereas some farmers kept their animals under the shade of tree and very few housed their animals in a separate shed. The findings were similar to the findings of Kumar et al. (2005) who reported that only $10 \%$ of the farmers studied kept their buffaloes in separately located sheds. The shelter of animals might be taken as a consequence of the economic value of the area and the remunerative nature of the farm. In case of roof type, thatched roof was provided to the shed by majority of the farmers in Rangareddy, Vikarabad, Medak, Nalgonda and Mahaboobnagar with $36.67 \%, 40 \%, 46.67 \%, 40 \%$ and $43.33 \%$, respectively. This might be due to the medium income level of dairy farmers in study areas. Similar findings were reported by Varaprasad et al. (2013) who reported that among livestock sheds, $55.8 \%$ were covered with thatched roof, $33.63 \%$ were with asbestos roof and the remaining $3.2 \%$ were pucca sheds. Findings of Kishore et al. (2013) were also found to be in concurrence with the findings of the present study. In the entire study area, very few farmers (8\%) provided pucca roof to their animals showing the small scale nature of dairying in the rural areas. Mud flooring was found to be the dominant type of flooring practiced by the farmers followed by cement concrete and slab stone and these results were similar to the findings of Kumar et al. (2005), Bainwad et al. (2007), Singh et al. (2007), Shitole et al. (2009) and Kishore et al. (2013) who reported that majority of the farmers had kutcha type flooring according to their economic status. Majority of the farmers in the study area were not providing the animal feed in a manger. Instead, in the shed an area was created with the help of long stone slabs to provide feed to their animals, which indicated the prevalent practice in the rural Telangana.

The provision of drainage facility was a common practice observed in the study area in contrary to the results of Deoras et al. (2004) and Shitole et al. (2009) who reported that the drainage to drain out urine was not available in majority of animal sheds. The present study revealed that in all the five districts studied, majority of the farmers provided sufficient space to their animals, giving comfort of movement. These results were in agreement with the results of Deoras et al. (2004). Most of the farmers (61.33\%) maintained cleanliness in the shed with regular disposal of manure $(68 \%)$ and regular cleaning of tying area $(68 \%)$.
Regarding the summer management, in the entire study area majority of the farmers $(52 \%)$ did not practice any management practices to protect dairy animal from extreme heat in summer which might be due to lack of awareness or preoccupation with agricultural operations.

\section{Feeding management practices}

The results regarding the feeding management practices followed by the dairy farmers in the study area are presented in Table 2. It is observed that most of the farmers from all five districts were sending their animals for grazing similar to the findings of Ahirwar et al. (2010), Rathore et al. (2010) and Manohar et al. (2014). The results might indicate the availability of the grazing lands and using grazing as a supplementary source of feeding for their livestock. In Rangareddy, Vikarabad, Medak and Nalgonda districts, majority of the farmers provided the feeding area within the shed but in Mahaboobnagar, very few farmers were providing the feeding area within the shed. Majority of the farmers in Vikarabad, Medak, Nalgonda and Mahaboobnagar were following group feeding and percentages were $66.6 \%$, $63.33 \%, 80.00 \%$ and $86.6 \%$, respectively in accordance with the results of Rathore et al. (2010) and Manohar et al. (2014). In contrary to the available literature, farmers from Rangareddy mostly followed individual feeding, which might be indicating the knowledge of farmers about the importance of the individual feeding based on the level of production.

Majority of the farmers from Medak and Mahaboobnagar districts were following one time feeding to their animals indicating the lack of awareness of the importance of scientific feeding. However, most of the farmers from Vikarabad (66.67\%) were offering feed two times while in Rangareddy and Nalgonda, majority $(66.67 \%$ and $63.33 \%$ respectively) of the farmers were offering feed three times during morning milking, evening milking and night time which might be attributed to the fact that farmers from these two districts were more aware about scientific feeding.

Most of the farmers from Vikarabad, Medak, Nalgonda and Mahaboobnagar were producing fodder by themselves that might be due to the availability of cultivatable land with sufficient water sources. But, most of the farmers from Rangareddy district were procuring fodder from other sources due to the non availability of land for cultivating the fodder in the area as more urbanization was taking place in this region because of its proximity to Hyderabad city where land conversion and value was very high. It was found that majority of the dairy farmers in Rangareddy, Vikarabad and Nalgonda were aware of scientific feeding while very few farmers from Medak and Mahaboobnagar were aware of the importance of scientific feeding. It was also observed that only $19.33 \%$ of the farmers were practicing the practice of chaffing the fodder before feeding and very few farmers provided supplementary mineral mixture to their animals that might be due to the lack of knowledge about principles of scientific feeding.

Dairy farmers from all the five selected districts had sufficient water to meet the requirements of their animals. 


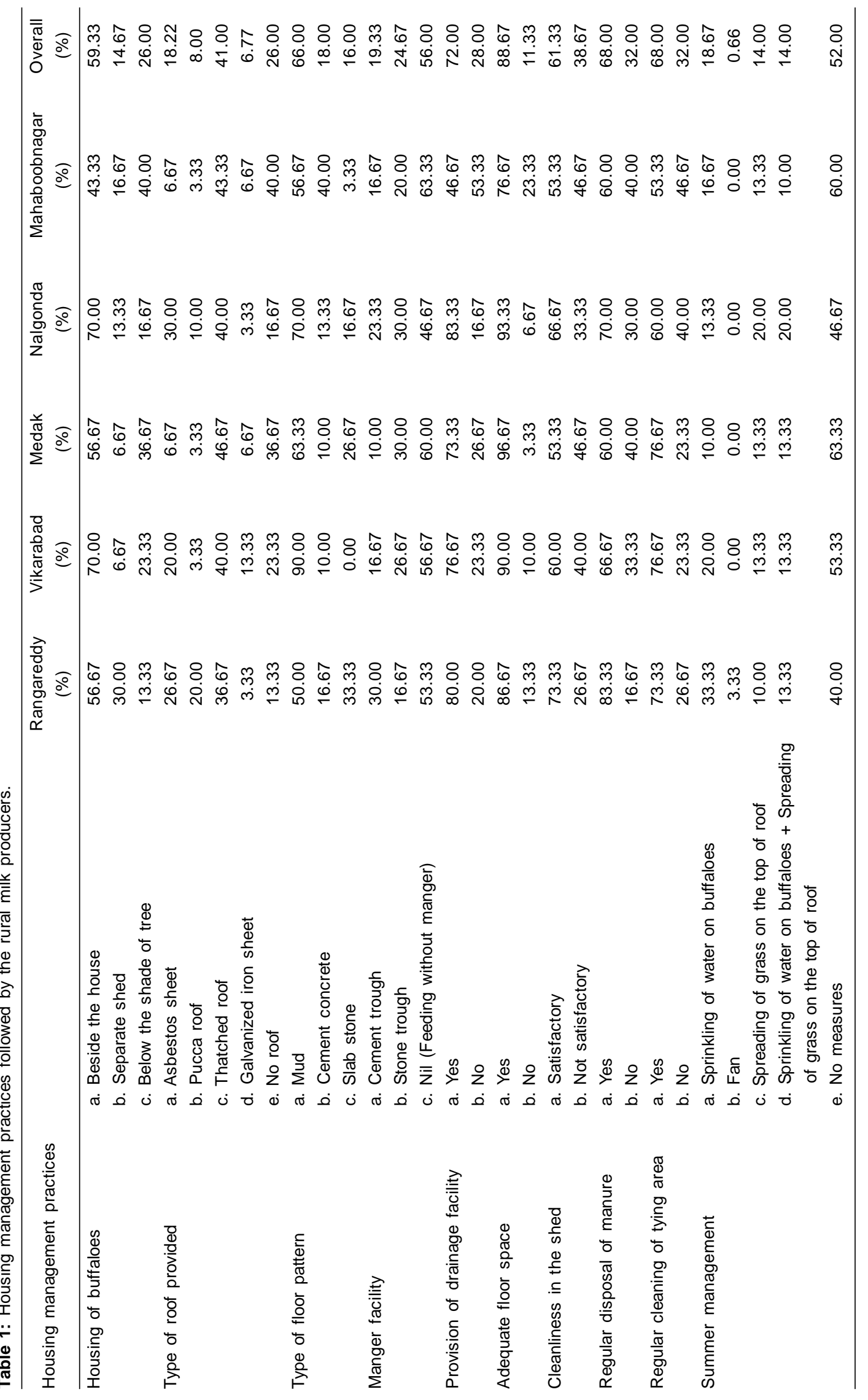


Table 2: Feeding management practices followed by the rural milk producers.

\begin{tabular}{|c|c|c|c|c|c|c|c|c|}
\hline $\mathrm{N}$ & Feeding management practices & & $\begin{array}{c}\text { Rangareddy } \\
(\%)\end{array}$ & $\begin{array}{c}\text { Vikarabad } \\
(\%)\end{array}$ & $\begin{array}{c}\text { Medak } \\
(\%)\end{array}$ & $\begin{array}{l}\text { Nalgonda } \\
(\%)\end{array}$ & $\begin{array}{c}\text { Mahaboobnagar } \\
(\%)\end{array}$ & $\begin{array}{l}\text { Total } \\
(\%)\end{array}$ \\
\hline \multirow[t]{2}{*}{30} & Animals sent for grazing & Yes & 100.00 & 86.67 & 90.00 & 100.00 & 100.00 & 95.33 \\
\hline & & No & 0.00 & 13.33 & 10.00 & 0.00 & 0.00 & 4.67 \\
\hline \multirow[t]{2}{*}{30} & Location of feeding area & Within the shed & 86.67 & 93.33 & 60.00 & 63.33 & 26.67 & 66.00 \\
\hline & & Separate & 13.33 & 6.67 & 40.00 & 36.67 & 73.33 & 34.00 \\
\hline \multirow[t]{2}{*}{30} & Type of feeding & Group feeding & 43.33 & 66.67 & 63.33 & 80.00 & 86.67 & 68.00 \\
\hline & & Individual & 56.67 & 33.33 & 36.67 & 20.00 & 13.33 & 32.00 \\
\hline \multirow[t]{3}{*}{30} & No. of times feed offered & 1 Time & 13.33 & 16.67 & 50.00 & 3.33 & 60.00 & 28.67 \\
\hline & & 2 Times & 20.00 & 66.67 & 30.00 & 33.33 & 33.33 & 36.67 \\
\hline & & 3 Times & 66.67 & 16.67 & 20.00 & 63.33 & 6.67 & 34.67 \\
\hline \multirow[t]{2}{*}{30} & Awareness of scientific feeding & Yes & 63.33 & 56.67 & 26.67 & 86.67 & 20.00 & 50.67 \\
\hline & & No & 36.67 & 43.33 & 73.33 & 13.33 & 80.00 & 49.33 \\
\hline \multirow[t]{2}{*}{30} & Fodder production & Produced & 43.33 & 66.67 & 63.33 & 93.33 & 86.67 & 70.67 \\
\hline & & Procured & 56.67 & 33.33 & 36.67 & 6.67 & 13.33 & 29.33 \\
\hline \multirow[t]{2}{*}{30} & Availability of water & Sufficient & 100.00 & 100.00 & 100.00 & 100.00 & 100.00 & 100.00 \\
\hline & & Not sufficient & 0.00 & 0.00 & 0.00 & 0.00 & 0.00 & 0.00 \\
\hline \multirow[t]{3}{*}{30} & Structure used as waterer & Water trough & 16.67 & 13.33 & 13.33 & 16.67 & 10.00 & 14.00 \\
\hline & & Bucket & 3.33 & 13.33 & 6.67 & 10.00 & 23.33 & 11.33 \\
\hline & & Cement tub & 80.00 & 73.33 & 80.00 & 73.33 & 66.67 & 74.67 \\
\hline \multirow[t]{2}{*}{30} & Chaffing practiced & Yes & 30.00 & 23.33 & 13.33 & 20.00 & 10.00 & 19.33 \\
\hline & & No & 70.00 & 76.67 & 86.67 & 80.00 & 90.00 & 80.67 \\
\hline \multirow[t]{2}{*}{30} & Mineral mixture feeding & Yes & 36.67 & 16.67 & 13.33 & 20.00 & 6.67 & 18.67 \\
\hline & & No & 63.33 & 83.33 & 86.67 & 80.00 & 93.33 & 81.33 \\
\hline \multirow[t]{3}{*}{30} & Feed and fodder cost (Rs/kg) & Green fodder & 1.00 & 0.90 & 0.95 & 0.75 & 1.00 & 0.92 \\
\hline & & Dry fodder & 4.00 & 3.00 & 2.50 & 2.50 & 3.00 & 3.00 \\
\hline & & Concentrates & 24.00 & 25.00 & 25.00 & 24.50 & 26.00 & 24.90 \\
\hline
\end{tabular}

The study revealed that water availability was not a constraint in all the areas studied and almost all the farmers were using cement tub to provide water throughout the day. In the studied areas, the average cost of green, dry fodder and concentrates were found to be Rs. $0.92,3.00$ and 24.90, respectively.

\section{REFERENCES}

Ahirwar, R.R., Ashok, S. and Qureshi, M.I. (2010). A study of managemental practices in water buffalo (Bubalus bubalis) in India. Buffalo Bulletin. 29(1): 43-51.

Aulakh, G.S. and Singh, R. (2015). Socio-economic characteristics of farmers and status of buffalo health care practices. Indian Journal of Animal Sciences. 85(12): 1396-1398.

Bainwad, D.V., Deshmukh, B.R., Thombre, B.M. and Chauhan, D.S. (2007). Feeding and management practices adopted by buffalo farmers under watershed area. Indian Journal of Animal Research. 41(1): 68-70.

Deoras Rajiv, Nema, R.K. and Mishra, U.K. (2004). Management practices of calves in Rajnandgaon district of Chhattisgarh plain. Indian Journal of Animal Sciences (India).

Kishore, K., Mahender, M. and Harikrishna, C. (2013). A study on buffalo management practices in khammam district of Andhra Pradesh. Buffalo Bulletin. 32(2): 54-56.
Kumar, M., Mehla, R.K. and Chandra, R. (2005). Feeding and housing managemental practices of Nili-Ravi Buffalo under field conditions. Indian Journal of Dairy Science. 58(5): 376378.

Manohar, D.S., Goswami, S.C. and Bais, B. (2014). Study on feeding management practices of buffaloes in relationship with selected traits of respondents in Jaipur district of Rajasthan, India. Indian Journal of Animal Research. 48(2): 150-154.

Rathore, R.S., Rajbir, S., Kachwaha, R.N. and Ravinder, K. (2010). Existing management practices followed by the cattle keepers in Churu district of Rajasthan. Indian Journal of Animal Sciences. 80(8): 798-805.

Shitole, D.P., Deshmukh, B.R., Kashid, U.B. and Chavan, R.R. (2009). Studies on management practices of bufaloes in Parbhani district. Indian Journal of Animal Research. 43(4): 251-254.

Singh, M., Chauhan, A. and Garg, M.K. (2007). Studies on housing and health care management practices followed by dairy owners. Indian Journal of Animal Research. 41(2): 79-86.

Varaprasad Reddy, A., Raghunandan, T., Kishan Kumar, M. and Gnana Prakash, M. (2013). Study on the management practices of the farmers rearing Jersey $x$ Sahiwal cows in Chittoor District of Andhra Pradesh. Scholarly Journal of Agricultural Science. 3: 86-88. 